\title{
POETICS
}

Poetics 27 (2000) 69-90

www.elsevier.nl/locate/poetic

\section{Becoming a Nazi: A model for narrative networks}

\author{
Peter S. Bearman ${ }^{\mathrm{a}, *}$, Katherine Stovel ${ }^{\mathrm{b}}$ \\ a Institute for Social and Economic Theory and Research, Columbia University, \\ SIPA Building 814, Mailcode 3355, New York, NY 10027, USA \\ b 202 Savery Hall, Department of Sociology, University of Washington, \\ Seattle, WA 98506, USA
}

\begin{abstract}
This article illustrates a strategy for representing and analyzing narratives as networks. The strategy that we use considers narrative sequences as networks. Elements are treated as nodes which are connected by narrative clauses, represented by arcs. By representing complex event sequences as networks, inducing 'narrative networks', it is possible to observe and measure new structural features of narratives. The narratives we focus on are autobiographical accounts of becoming, and being, a Nazi. The substantive idea that we develop in this article is that the observable narrative structure of life stories can provide insight into the process of identity formation. We illustrate our approach to narrative networks by analyzing a single story that, in conjunction with the analysis of other stories, yields a set of insights into becoming and being. (C) 2000 Published by Elsevier Science B.V. All rights reserved.
\end{abstract}

$\Rightarrow$ The idea for this article has a long history. First drafts were written in 1992 and 1993, and these early versions were presented at various conferences and colloquium. Subsequently both the idea and the paper were consigned to the gnawing criticism of squirrels. (Actually, sometime between 1993 and 1998, a squirrel made a nest in the box containing the drafts and raw data.) John Mohr suggested that we resuscitate the ideas. There is still much work to be done. Weaknesses are our responsibility, despite the advice we have received, from, among others: Andrew Abbott, Hannah Brückner, Craig Calhoun, Aaron Cicourel, Larry Griffin, Eric Leifer, Kent Redding, Douglas White, and Harrison White. We owe a special debt to Connie Witte for her able translations of many life stories, and to John Mohr whose interest and enthusiasm for this project brought it to light.

* Corresponding author. E-mail: psb17@columbia.edu 
"A tragedy is impossible without action, but there may be one without actors." (Aristotle)

\section{Introduction}

This article illustrates a new, network-based, strategy for representing and analyzing narrative sequences. While the strategy we develop is applicable for all narratives, the narrative sequences we focus on for illustration are autobiographical accounts (written life stories) of becoming, and being, a Nazi. Life stories, like all stories, consist of sets of elements that are woven together (sometimes more and sometimes less) into a narrative sequence in order to account for some change in a situation, from the beginning of the sequence to the end (Labov and Fanshel, 1977; Labov, 1972). Stories accounting for events or outcomes are necessarily common in everyday life, for people construct stories to account for non-canonical events that cannot otherwise be accounted for by culturally agreed upon narrative expectations. ${ }^{1}$ Telling stories always involves arraying elements selected from a rich and inexhaustible plate of cultural goods - people, places, things, events, ideas, and so on into narrative sequences that are oriented toward a particular end, in such a way as to make up what we typically call a 'plot'.

Narratives provide one mechanism for organizing and generating social meanings. The salient social meaning generated in life stories is the identity that the story yields. The specific idea that we develop in this article is that network representation of the narrative structure of life stories provides insight into the process of identity formation. The general idea is that network representation of narrative sequences provides insight into the social meanings generated within narratives as a whole. Our specific substantive goal is to explore some of the pathways through which ordinary men and women became Nazis before the seizure of power. In somewhat fancier terms, in this article, we model the construction of Nazi identity, for early adherents of the movement. The strategy that we use considers narrative sequences of elements

\footnotetext{
1 We are not suggesting that the method we develop here is applicable only to odd stories. By noncanonical we do not mean pathological or disturbed. Canonical expectations are the fundamental expectations that organize our experience. These expectations tend to be extremely simple. One example is the 'continuity principle' that governs our daily experiences. The continuity principle (as canonical expectation) asserts, for example, that when driving, our car will continue to go down the road, that empty spaces behind and in front of us will not suddenly become full of things, and that the road behind us will stay behind us even after we have driven past it, as will the road in front, and so on. It is culturally impossible to tell stories in which all of the elements are organized by canonical expectation; for example, 'I went for a walk and after I put my left foot down I put my right foot down and then my left foot down and ... And when I turned around the path that I had been walking on was still there' is only a promising beginning of a story if a non-canonical event (the path disappeared, for example) around which a story could be organized is introduced. Abstracted to life stories, there is a more general point. Life stories are accounts of how we became who we are. Once it becomes possible to tell a life-story, the account that is told cannot by definition be canonical, e.g. the life lived is the inexorable byproduct of the canonical way of life, for example, the life of the peasant for whom death is meaningful. Life-stories are consequently a hallmark of modernism.
} 
as networks. Elements are treated as nodes which are connected by narrative clauses, represented by arcs. $^{2}$ By representing complex event sequences as networks, we are easily able to observe and measure structural features of narratives that may otherwise be difficult to see. There are good reasons to think that insight into the structure of narrative processes may be revealed by network methods that provide insight into social structure. One simple reason is that narrative data and 'network data' have many obvious similarities. Specifically, narrative, historical, and network data are locally dense, often cyclic, knotted, and characterized by a redundancy of ties. These similarities suggest that the analysis of narratives and event sequences using network methods may provide a promising avenue for analysis. Illustration of simple network applications to narrative sequences is a goal of this article.

By 'narrative network', we refer to a strategy for representing narrative life histories as networks of elements. Applying standard network techniques to this representation of the narrative, we are able to identify some core elements of the process by which individuals became Nazis (hereafter, becoming). Though our substantive emphasis is on becoming, our data also allow us to consider the narrative structure associated with being a Nazi, and to contrast becoming with being more generally.

\section{Overview}

While the method we develop is applicable to all narratives, we are especially interested in considering how the analysis of narrative networks can contribute to solving substantive problems in historical social science. The substantive problem we consider in this article is how seemingly ordinary people became Nazis. The more standard framing in the social sciences is to ask why people became Nazis, thereby ignoring the becoming process. The focus on narrative networks enables one to simultaneously consider issues of content (why) and issues of form and process (how). The problem posed by the early adherents of the Nazi movement - the people who made the seizure of power possible - is that the process of becoming a Nazi reveals that the twin foundations upon which traditional answers to the 'why' question are based (interests and/or social relations) are analytically fragile.

Against this background, we begin by briefly discussing traditional approaches to the problem of accounting for social action in historical sociology. We then describe our method in more detail. We illustrate our approach to narrative networks by analyzing a single story that, in conjunction with the analysis of other stories, yields a set of insights into becoming, and being. Our analyses exploit simple network measures that take us down a picaresque narrative river. On the way, we illustrate new strategies for analyzing narrative sequences, and point to interesting insights that

\footnotetext{
2 A narrative clause is a clause that is temporally ordered in such a way as moving it involves changing the meaning of the sub-sequence in which it is embedded. Free clauses, by contrast, can be moved without changing the meaning of a sub-sequence, or the narrative as a whole. Stories contain both free and narrative clauses (Labov, 1972).
} 
arise from each strategy. ${ }^{3}$ We show that narratives accounting for the processes of becoming have an identifiable structure that is absent in accounts of being. We conclude by discussing how the central methodology developed in this article can be utilized to analyze narratives of diverse scope, not limited to life-stories.

\section{Data and historical context}

The specific process we consider, becoming a Nazi, is an important one. At the most fundamental level, the National Socialist German Workers' Party (NSDAP) was able to seize power in Germany because a significant number (around 250,000) of otherwise ordinary German people had, before the seizure of power, come to see themselves as Nazis. That is, large numbers of Germans somehow took on (and, also constructed for others) a Nazi identity. After the seizure of power, becoming a Nazi often appeared to be a pragmatic thing to do, and perhaps it was. But before 1930, becoming a Nazi was non-normative. It was not pragmatic, it involved high costs and high risks, and it was not a routine event.

The set of life stories from which we draw our data were written in August 1934 (just a year after the NSDAP consolidated power, and before widespread knowledge of the final solution), by people who joined the movement before the seizure of power, typically before 1930 and often earlier. The stories were submitted in a contest for the best life story of an adherent of the Nazi movement. ${ }^{4}$ The competition was organized by Theodore Abel (a sociologist at Columbia University), but sponsored by the NSDAP and SA. A cash award was to be given to the best essayist. Some of the authors who contributed stories were likely trying to win the competition for money; others may have wanted to win favor with their superiors. Roughly 600 stories were entered into the competition. Most of the authors joined the movement before 1930, when there were few Nazis (in fact, the contest participants represent a 1/400 sample of early party members, Merkl, 1977). These men and women were not the leaders of the movement, but they were important players. Many rose to fill positions of considerable importance as group leaders, party officials or dis-

\footnotetext{
3 We are a long way from an integrated theory of becoming and being that would allow us to straighten out the curves in the river. Here we are content to see them.

4 Others have used the stories we work with (Abel, 1938; Merk1, 1977; Rhodes, 1980). Merkl focuses on the composition of the movement. His methodological strategy is standard fare in historical sociology; attributes of individuals; SES, religion, age, education, and the like, are extracted from narrative. The fact that an author happens not to mention their schooling, family life, religion and so on, are treated as missing data. Merkl's analysis rests on crosstabulations of disembodied attributes. Real lives are lost in the process, and real process is lost in the movement away from narrative by this abstraction. The role of narrative is reduced to local color that serves to flavor the otherwise tasteless cut and paste job that this method implies. In contrast, Rhodes works on the stories directly, but without a method, he gets trapped in a rhetorical element of stories of becoming fate. Seduced by the fatedness of the narratives, a characteristic of teleological thought and a feature of life stories (the work of a story is the revelation that 'accidents and chance' are only accidents and chance when seen in isolation), Rhodes interprets the Nazi movement as fated mysticism, as a millenarianism. Unable to penetrate beneath the rhetoric of fate to yield pattern in the process of becoming, Rhodes is lost in the teleology.
} 
trict heads (Merkl, 1977; Kater, 1983). The Nazi movement depended on these early joiners. Their activities and contributions carried the party beyond shifting attention cycles and electoral downswings, they prepared the ground for others to join, and thus ultimately they contributed to the seizure of power. In short, the actions of the early NSDAP members made possible the Third Reich. There is much to be gained from understanding how these people came to see themselves (and be) as Nazis. Similar dynamic becoming processes are also likely to operate in other contexts in which individuals adopt revolutionary identities that prescribe this worldly action in pursuit of movement goals, as well as for more mundane conversion narratives and the narratives of adherents of Alcoholics Anonymous.

\section{Theoretical orientation: Narratives and historical social science}

A central problem in historical sociology, and historical social science more generally, is what constitutes a plausible account of human action in historical context. In general, social scientists work with two often (but not necessarily) competing accounts of human action. The first type of account rests on interests that actors have, the second rests on actors' sense of self, or identity. Both accounts (as well as accounts that combine the two frameworks) provide theoretical models for bridging the gap between individual characteristics and observed social behavior. Both accounts seek to answer the question of 'why' people do things. For some problems in historical sociology, these strategies may provide a partial foundation for understanding, although we do not believe fully adequate answers to why questions (with respect to motive and/or content) are possible without understanding interest and identity formation processes.

Accounts of action based on interest assume that actors act with purpose to advance their interests given the information that they have. Interests are associated with positions in civil society, and people who occupy such positions are assigned the interests that are associated with them. ${ }^{5}$ If actors act in accordance with the interests they have been assigned, then they are 'rational actors'. With respect to the NSDAP, this strategy has led to a number of findings in the literature, for example the finding that members of the petty-bourgeoisie were 'rationally' supporters of the NSDAP (Brustein, 1996). The general problem with this approach is that because the future conditions the meaning of the past, ex post outcomes only come to be associated with presumed ex ante motivations at the end of behavior sequence. Only by ignoring this problem can one consider interest-based analytic strategies to contribute to our understanding of the meaning of an event sequence. For our case, the specific shortcoming is more prosaic: the process of becoming a Nazi involved the negation of interests - at least the negation of interests conventionally understood as

\footnotetext{
5 Of course they may not 'have' these interests, or if they 'have' them they may not recognize them. Consequently they will not act purposefully with respect to them. But this is the 'testable' component of the theoretical model. If one can construct interests that ex post could be seen to lie behind behavior, the imputation of motive (e.g. interest) as a plausible account is confirmed.
} 
arising from structural positions in civil society, and hence stands in an uneasy, perhaps orthogonal, relationship to interest-based theories.

Alternatively, a number of sociologists have recently focused on the relationship between identity and social action. Because individuals associate with persons who are similar to them, individuals tend to be embedded in relatively dense clusters of social relations in which the values that they hold and their sense of self are shared by and shaped by the others with whom they interact. Consequently, social sources of identity are seen to play a critical role in shaping action. ${ }^{6}$ Relational identity models bridge the gap between social relations and action through explicit or implicit reference to homophily. ${ }^{7}$ This strategy presumes that social relations meaningfully constitute identity. To solve endogeneity problems, ex post imputation of ex ante conditions is always necessary. Equally problematic, operationalizing identity as relational presumes that all identities are produced and sustained within interacting relational networks. This is not necessarily the case, ${ }^{8}$ and it is not the case for the becoming process we describe below.

Neither interest nor relational identity (nor fusion) models provide a way to bridge the gap between individual characteristics (seen in terms of group membership and/or relational embedding) and observed action aside from ex post imputation of motive. In this article we propose a simple strategy for bridging this gap directly. This strategy works without imputation of motive, and without recourse to abstractions that propose independent and largely non-measurable effects of 'culture', 'symbolic constructions', or 'cultural agencies' (Emirbayer and Goodwin, 1994).

6 For example, Paul Willis shows in Learning to labour (1977) how patterns of association amongst a group of working class youth generate and reproduce cultural commitments to manual labor. Similarly, Traugott (1986) shows how patterns of residential integration by social class in French cities blocked possibilities for neighborhood-based working class movements, whereas Gould (1995) shows how neighborhood solidarity facilitated some forms of collective action while blocking others. In these models, social identity is revealed though homophily within groups on some 'content'.

7 The classical example of the difference between interest and identity is Marx's (1963) analysis of peasants, who share objective interests (class-in-itself) but not self-conscious identity (class-for-itself). Bearman's (1993) fusion model shows how blockmodels of social relations simultaneously realize both interest and identity to predict social action. Blocks of structurally equivalent actors share the same set of interests. When such blocks are also 1-blocks (e.g., are tightly clustered in cohesive interacting subgroups) they also reveal self-conscious identity arising from homophily. Blockmodels provide one method for revealing when interests and identity overlap to make possible self-conscious purposive social action. In this model, the gap between interest and action is reduced by introduction of an intervening variable (social identity). Bearman (1993) argues that the identity-action gap is bridged by practice. Similarly, Bourdieu (1990) argues for the importance of habitus, a concept that expresses the simultaneity of practice and identity.

8 Anderson (1991) also argues that identities can emerge that are independent of tangible social relations, constituting forms of imagined communities. Often, for example, these are expressed as nationalism. Relational models of identity can, however, satisfactorily account for such identities, replacing ties between persons, with ties between persons and symbols. Sophisticated network models allow for joint visualization of symbolic and tangible networks, using lattice representations (Mische and Pattison. 1999; Mohr and Duquenne, 1998). Yet these representations, while descriptively powerful, fail to provide a mechanism by which the symbolic attachments of individuals are translated into action. However one conceives of identity as tangibly constructed through patterns of association (between persons or values or ideas), the gap between identity and action remains. 
Our strategy makes use of actors' narrative accounts of their own becoming experiences. We represent actors' theories of the self as narrative networks, and show that patterns in these accounts reveal an underlying process of 'becoming', thereby providing insight into the mechanisms by which identity as a social actor is produced. The position and role of elements reveal motive endogenously, in the narrative sequence of elements that make up a life story. ${ }^{9}$ The example we use involves identity formation (becoming and being a Nazi) but the method is theoretically applicable to a wide range of narrative sequences.

\section{Identity production and life-stories}

By identity, we refer to a subjectively held sense of self as an actor in the world that gives rise to action which is expressive of, and constituted by, the identity that underlies it. In most instances, identity is attached to settings, to particular others (as role complements), and to contexts. The identity formation process is typically the product of the accretion of relationships. Its narrative account is consequently an account in which elements (relations, persons, settings) are drawn to an emergent 'self', like iron filings under magnetic influence. Here we are interested in the process by which a specific form of identity - what we call a master identity - is produced. By a master identity we mean an identity that gives rise to action which is insensitive to context. Everyday identities give rise to action that expresses, and is constructed through, its relational basis. It is a poor father who acts as a scientist to his children. The adoption of a master identity means that action, not the relation/action pair provides the basis for identity. ${ }^{10}$ Since the master identity is insensitive to others, it cannot be built from relationality with others. The master identity's insensitivity to relational context means that it is potentially revolutionary if directed towards this-worldly activity. ${ }^{11}$ The specific problem we confront is modeling the process of becoming when it operates through the elision of social relations, as is necessarily the case with master identity formation.

\footnotetext{
9 Just because we model authors' accounts does not mean that we are restricted to representation of these accounts as revelatory of the motive that they explicitly articulate. Our argument is that narrative structures reveal motive - even if authors are blind to the underlying process or do not have the capacity to theorize the becoming process explicitly.

10 Some examples may help. Alcoholics (those who have gone through AA, and so consider themselves alcoholics) are alcoholics in all their social relations (Cain, 1987). Flagellants beat themselves whether anyone is watching or not as an enactment of the millennium. The action-set of Puritans is the same whether the relation acted on is a 'father' relation or an 'acquaintance' relation.

11 The Nazi identity is the most frightening of the master identities that have emerged in the $20^{\text {th }}$ century. As with other master identities, achievement of one results in a totalization of self and an emptiness of self as well (Arendt, 1973). The self is empty of the usual relational markers of distinction that we have - our roles as fathers or husbands or mothers or workers and whatnot. For these roles are necessarily tied to discrete particular individuals and carry discrete and different obligations and actionsets. People with a master identity are empty in the sense that their self acts independently of specific others.
} 
How then, do identities, and master identities specifically, become constitutive of individuals? As suggested above, in order to answer the how question - the process question - we need different kinds of data that allow different orienting questions than those typically posed in sociological theories of action. A basic requirement is that our data structures must be longitudinal (though they need not be prospective). That is, they must be capable of revealing process. A more fundamental requirement is that our data reflect the elements that organize the process, as versus those selected from the analyst's hat. One source of data that meet both requirements are life stories. Life stories provide an 'endogenous' account of how authors got from 'there' to where they are. Just like theories, life stories organize facts (elements, states, events, etc) into interpretable sequences and patterns to reveal a process. ${ }^{12}$ Here we focus on this process.

\section{Analytic strategy}

The foundation of our analytic strategy rests on representing life stories - the textual narrative accounts of how early adherents became Nazis - as networks. This is accomplished by coding as a node every discrete element within the narrative and then representing the author's explicit connections between elements (narrative clauses) as arcs linking elements. Arcs between elements are coded as present if one element 'leads to' another. For example, one section of the story we focus on here describes the significance of receiving a pair of brown trousers:

'When I was sixteen years old my mother bought me some brown trousers. If she had known the significance of this color, she would never have bought them for me. I told her that they pleased me, and she also bought some for my brother ... Now I felt as though I were half a Nazi.'

Our coding isolates the discrete elements of the story, in this case, identifying events like the purchase of the trousers, that they pleased him, that he told his mother that, that she then bought some for his brother, and that he 'felt like half a Nazi' as unique narrative elements, or nodes. Links between nodes are those present in narrative time they are the connections, or imputations, made by the author in putting the story together. A sociometric graph representing this narrative sub-sequence is shown in Fig. 1. The narrative complexity of this episode is revealed by the knotty and overlapping pattern of links connecting the discrete nodes.

12 The revelation of facts does not guarantee that the facts will be indicative of a reality exogenous to the life story. Sociologists who have used life stories as data tend to deny this, but it is a mistake to imagine that jumping out of the narrative is a trivial sort of exercise. Assuming that life stories reveal a meaningful external reality, sociologists tend to ignore the story and focus on the life external to the story (Elder, 1974; Clausen, 1993; Peacock, 1986). This strategy embraces the weaknesses of stories and runs from their strengths. The strength of stories is that they are accounts of process. Cf. Bruner, who notes that "the second feature of narrative is that it can be real or imaginary without loss of its power as a story. The sense and the reference of a story bear an anomalous relationship to each other. That narrative is indifferent to extra-lingusitic reality underlines the fact that it has a structure that is internal to discourse" (Bruner, 1986: 44). 


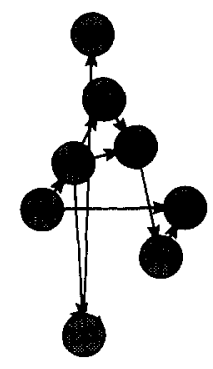

Fig. 1. Graph representation of subsection of narrative network.

We use the technique of identifying nodes and arcs to code the entire story, generating an adjacency matrix denoting the ties between elements within each story. From each matrix we induce graphs that represent the narrative from which they arose: the complete graph associated with the story we rely on for our illustration is shown in Fig. 2. As we conceive them, graph representations are isomorphic with the narrative, and it is possible to reconstruct the original life story from the graph. ${ }^{13}$ Event sub-sequences with dense and complex inter-relationships between elements appear as knots, simpler narrative sequences with less causal density appear as chains. The absence of narrative connections between elements is indicated by an absence of arcs. The graph suppresses real time if the causal narrative suppresses real time. In real time, the graph reported in Fig. 2 describes events from 1916, when the author was five years old, to 1934, when the author (at age 23) wrote his life story. Between 1916 and 1930 (the becoming portion), the story consists of 139 unique identifiable narrative elements; between 1930 and 1934 (the being portion), the story contains 142 unique narrative elements. There is no necessary relationship between element frequency, sub-sequence density, and real time. Our representation of narratives as networks relies solely on narrative time.

\section{Structural features of graphs: Contrasting the becoming and being narra- tives}

Representing narratives as networks allows one to identify obvious patterns in the structure of narratives. The graph represented in Fig. 2 reveals two different structures, here highlighted by shading. The left half of the life story, associated with the author's account of becoming a Nazi, is knotty and densely tied. The right half, associated with being a Nazi, is composed of small and disjointed components (narrative sub-sequences). In the becoming narrative, all elements are tied to at least one other

13 Our representations involve a compromise between three different principles: narrative time should flow from left to right, elements close to one another in the causal narrative should be close to one another in the graph, and the number of crossing lines should be minimized, but this is simply to aid in interpretation. 


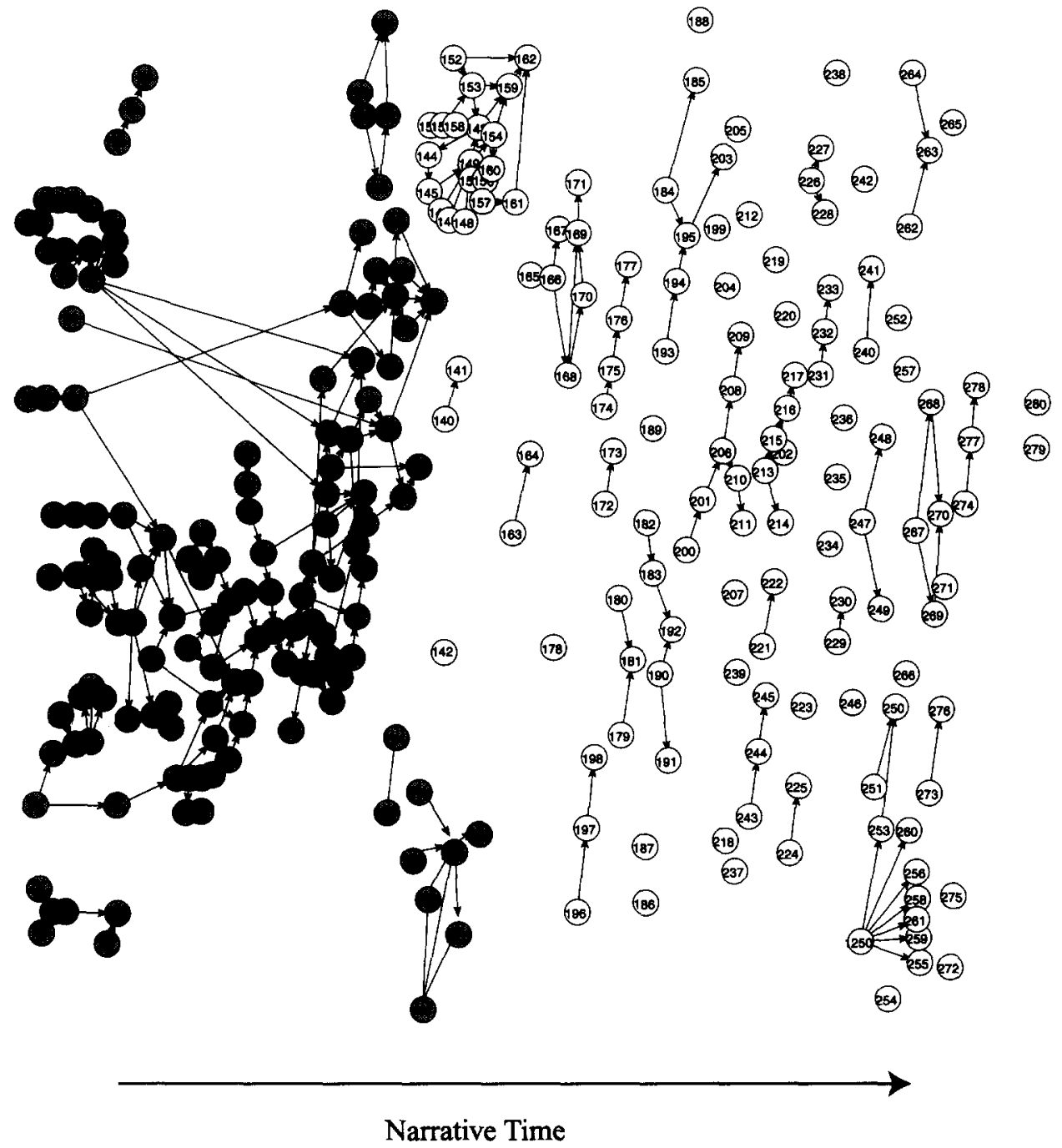

elements in becoming story $\mathrm{O}$ elements in being story

Fig. 2. Narrative structure of nazi life history. 
node: not a single element is a pure isolate. This is in sharp contrast to the being narrative, in which $27 \%$ of all nodes $(n=34)$ have no tie to any other node. These visual impressions are confirmed by comparing the density of the two parts of the narrative: the becoming narrative is twice as dense as the being narrative. ${ }^{14}$

Narrative density is the product of the theory of the life-story. The absence of connections between elements or sub-sequences implies the absence of theory, or plot. ${ }^{15}$ The being story is the denouement of the becoming process, yet it is not the case that we should expect the absence of narrative density, for authors of stories select the elements that they work with on the basis of an organizing theory. These elements should compose sub-sequences of loosely coupled events, unless the theory governing the selection of events is decoupled from the narrative account. We return to the significance of this decoupling further below.

The formal component structure of each half of the story is shown in Fig. $3{ }^{16}$ The becoming narrative is dominated by one large component of 116 inter-connected events. Two relatively small components (nodes 117-122; and nodes 124-128) towards the end of the becoming narrative are disconnected from the becoming process. ${ }^{17}$ A few small components at the start of the story are also disconnected from the large component. ${ }^{18}$ In contrast, the being story is dominated by isolated events and extremely small components; it is impossible to travel through the being story from its beginning to end. The absence of connective structure in the being story makes meaningless many standard social network analysis techniques, ${ }^{19}$ which capture the heterogeneity of nodes with respect to their position in the overall network.

14 The narrative of becoming has a density of 0.0174 ( $\mathrm{n}$ of nodes $=139$ ) while the being narrative has a density of 0.0093 ( $n$ of nodes $=142$ ).

15 Parsimonious theories will yield thin connected graphs like spanning trees. Complex theories will lead to cycles and cores; the absence of an organizing theory will lead to isolated nodes. Therefore the overall relationship between density and theory is curvilinear.

16 Technically, a component is a complete set of nodes tied by arcs in a graph. If all nodes in a graph are connected, the graph contains a single component.

17 These two subsequences involve school. In the first, the author sees a NSDAP parade while at school, and describes the attitudes of his teacher (SPD), other students, and his courses. Despite the fact that his German teacher was SPD, he liked German the best of all his subjects. In the second sequence (124-128), the author tries to leave school for the first time and is threatened by his father. Subsequently, he leaves school anyway and achieves an inner clarity that connects him to dead soldiers and the fatherland.

18 These events involve Jews. The author has a number of experiences with Jews. He integrates one set of experiences (fighting Jews after getting his brown pants), but fails to integrate other experiences (a Jew gives him sweets, but he never eats them), and his brother dies after an 'unnecessary operation' conducted by a Jewish doctor. In other narratives Jews and relations with Jews, also tend to have low centrality and be in smaller disjoint components.

19 For example, it is impossible to induce a meaningful role structure of the elements in the being story. Likewise, many measures of central graph tendencies (centralization, for example) while calculable, are not helpful. 


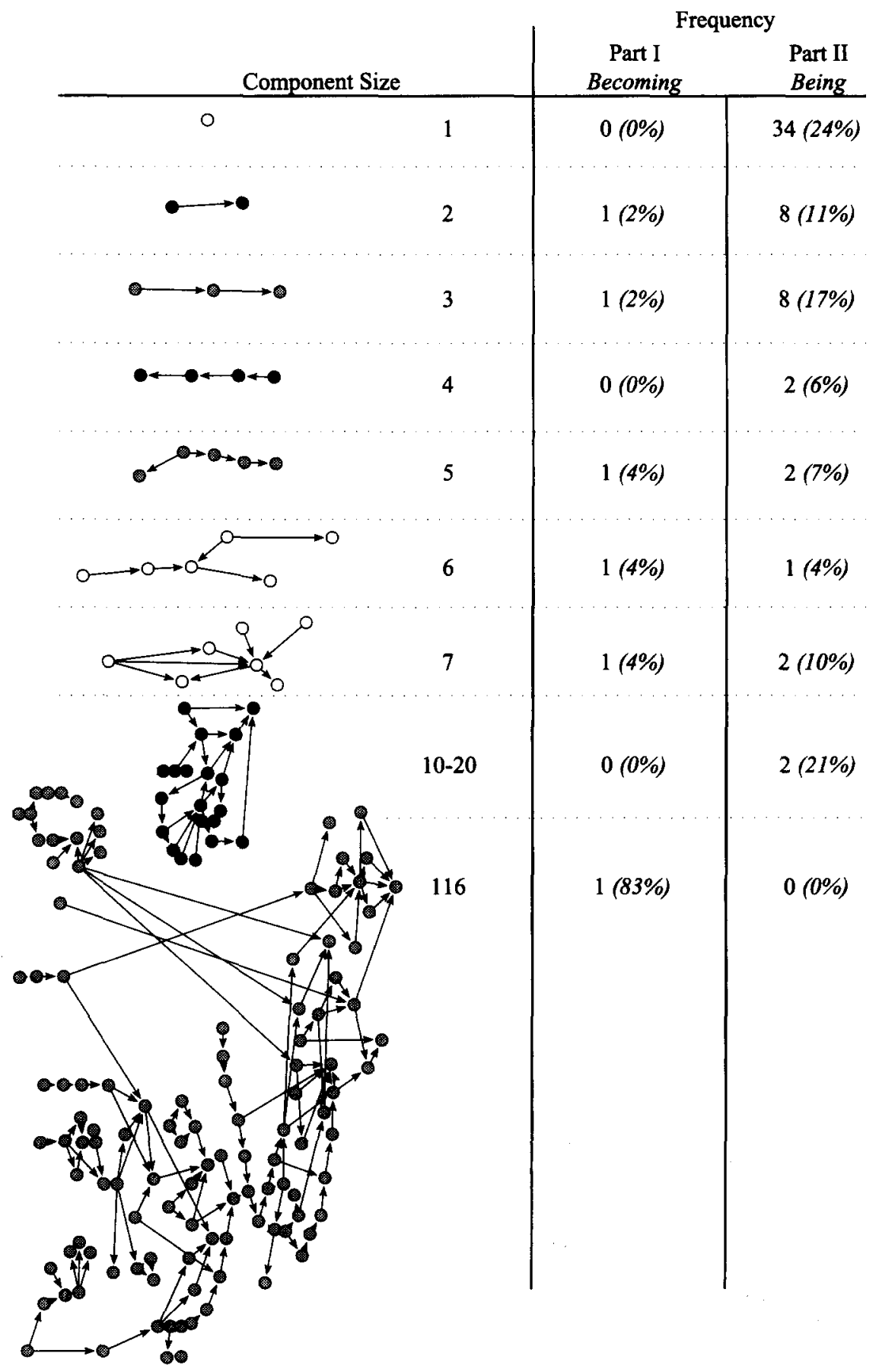

Fig. 3. Distribution of n-sized components in narrative. 
It is possible, though, to think about narrative depth as a meaningful structural feature of narrative networks. The simplest measure of narrative depth is the length of the shortest direct path from the beginning of a component to the end. In the becoming story, the longest shortest path (geodesic) involves 23 steps. The fact that the most 'efficient' becoming pathway, the core of the process, involves 23 ordered elements ordered by narrative clauses makes clear that the becoming stories we focus on are not simple. In contrast, in the being story, the longest shortest path (which is embedded in the largest sub-component) involves 7 steps. Focusing on geodesic pathways suggests some new ways to conceptualize structural narrativity beyond direct element-toelement ties, specifically by identifying the core elements in the becoming process, elements which, if removed, would break the underlying plot into disjoint stories.

Fig. 4 reveals the necessary structural features of the becoming narrative by removing nodes (elements) that stand between two other elements in a single chain. Thus, for example, the chain $1 \rightarrow 2 \rightarrow 17$ is simplified through betweenness reduction to $1 \rightarrow 17$, eliminating the element ' 2 ' (going into the cellar to avoid bombs during the great war). In both halves of the narrative, roughly half of the events can be eliminated as fully redundant (72/139 vs. 69/142). Reduction of the becoming story yields a parsimonious representation of a single cohesive story. In contrast, reduction highlights the disjunctive nature of the being story.

While narratively redundant, events that are embedded in dense sub-sequences tend to have greater in and out degree (the number of other events that they are tied to). If one thinks of narrative as carrying all of the events of the related past into the future (both the direct tie representation of Fig. 2 and the reduced form narrative structure reported in Fig. 4 ignore all of the relations between elements that are implied by their carrying capacity), densely tied events have greater indirect reach. That is, they provide indirect connections between elements in a narrative, even above and beyond their immediate structural position.

Contrast between the structure of the first and second halves of the story is revealed most starkly by focusing on the proportion of all elements reached through indirect pathways in n-steps. Fig. 5 illustrates this contrast. The $\mathrm{x}$-axis indexes the number of steps, and the y-axis indexes the proportion of all elements drawn into the narrative at each remove. For each element, we calculate the total number of elements reached through chains of intermediary elements, and report the mean number reached. Because the being story lacks a theory (self) to link elements, no more than $15 \%$ of all elements are connected even under maximum narrativity, where the entire past is drawn into the future (and vice-versa).

The thinness of the being story is revealed under conditions of maximum connectivity implied by our focus on all the indirect connections between elements. The structure of the reach distribution - in this case, where we observe that more than $1 / 2$ of all elements in the becoming story can be reached with very few steps - provides insight into the dynamics of the becoming process. Here, as in all examples we have worked with, locally dense event sequences characterized by cyclical and knotted element-to- element relations are connected through bridge events. In the next section we focus on these bridge events, first with respect to their type, and subsequently with respect to their content. 


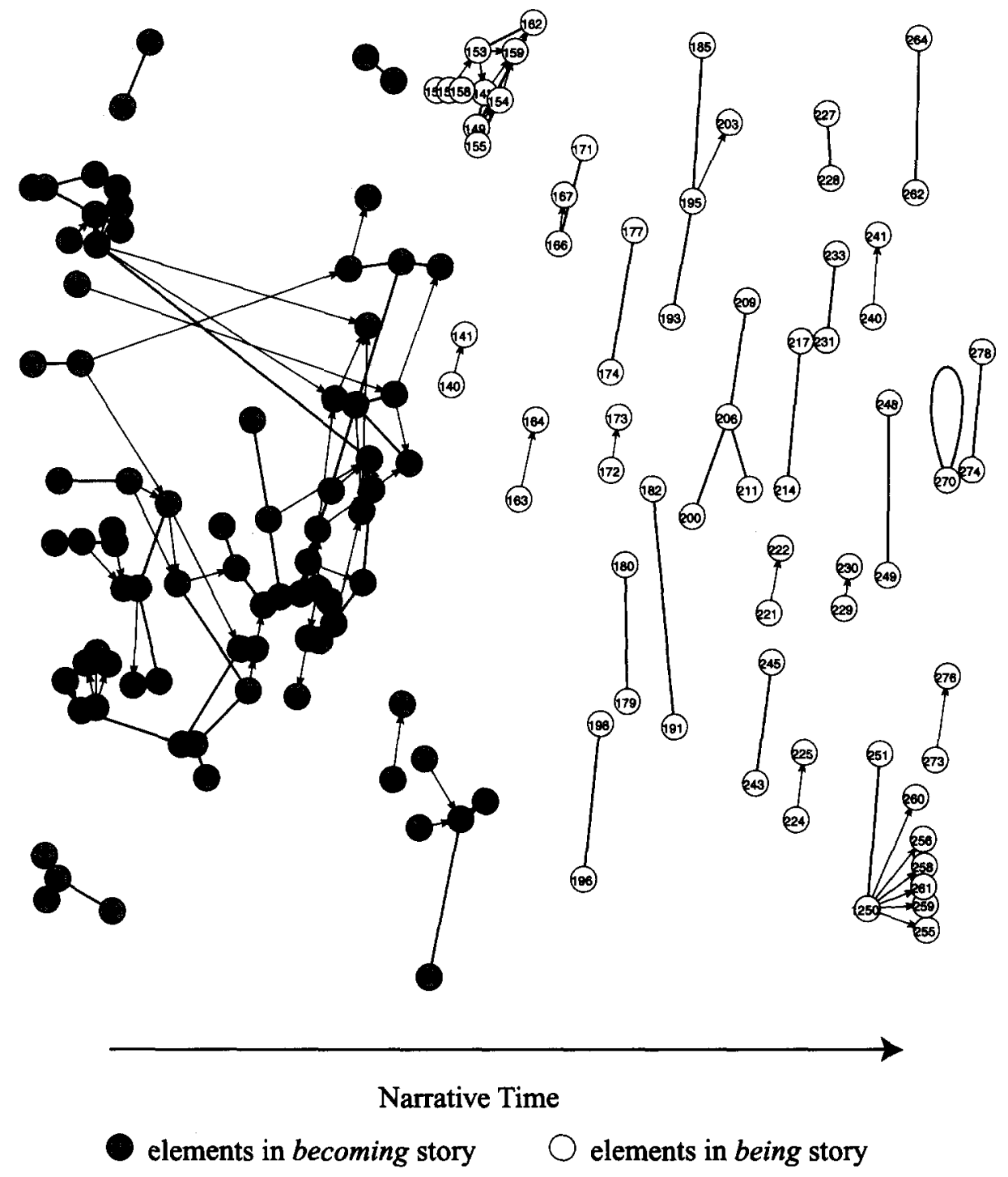

Fig. 4. Reduced form of entire life history. 


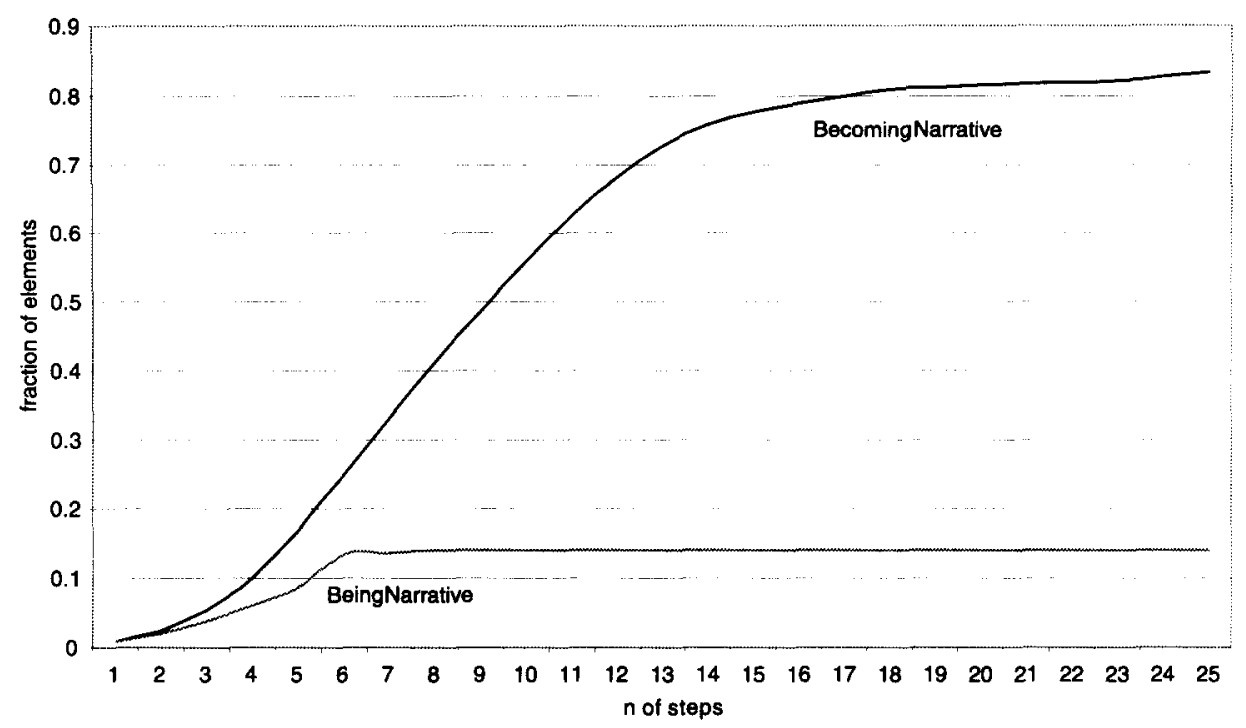

Fig. 5. Mean fraction of elements reached at n-steps.

\section{Types of elements}

Structural analysis of narrative networks allows for measurement of narrative characteristics independent of element content. In this section we illustrate how integrating structural properties of elements (centrality, betweenness, patterning of dyadic ties) with content allows for new insight into the meaning of elements, sub-sequences, and the narrative as a whole. The goal is to reveal an underlying morphology to narrative processes of becoming (and, where possible, being) a Nazi. The first problem to resolve is that the specific elements invoked in life-stories are heterogeneous. Comparison within and across narratives necessitates abstraction away from the particularity of specific elements. This is accomplished by grouping elements into equivalency classes. Here we define elements with respect to type and content.

We first distinguish between three classes of elements by type: macrolevel elements (M), local event elements (L), and cognitions (C). Macro-level elements are elements noted in the narrative that occur outside the author's local world. In this narrative, macro-level elements include the 'great war', the putsch, and rising inflation. Local event elements are ordinary events occurring in the author's local world. These are events that are experienced directly. In our illustrative story local elements include experiencing a childhood illness, wearing a swastika to school, and taking a bicycle trip with his sister. Cognitions are aspects of the narrative in which the author questions the meanings of elements, draws conclusions, or reveals a new cognitive understanding about his situation. Cognition elements include 'communists and Hitler both want power', 'recognizes the beauty of nature', and 'felt as if half a Nazi'. 
Table 1

Descriptive characteristics of narrative

\begin{tabular}{lcccccc}
\hline & \multicolumn{2}{c}{ Being (Part II) } & \multicolumn{2}{c}{ Becoming (Part I) } & \multicolumn{2}{c}{ Entire narrative } \\
\hline Type of node & $\mathrm{n}$ & $\%$ & $\mathrm{n}$ & $\%$ & $\mathrm{n}$ & $\%$ \\
\hline Macro elements (M) & 6 & 4 & 12 & 8 & 18 & 6 \\
Local elements (L) & 99 & 71 & 94 & 66 & 193 & 67 \\
Cognitive elements (C) & 34 & 18 & 36 & 25 & 70 & 25 \\
\hline N of Nodes & 139 & & 142 & & 281 & \\
\hline
\end{tabular}

Overall, macrolevel elements are rarely mentioned in the story (only $6.4 \%$ of elements are classified as macro-level elements). Inclusion of these events, while not driving the story itself, locates the narrative of becoming in real time. The bulk of the narrative is composed of local events, which are relatively evenly distributed across the two halves of the narrative ( $71 \%$ in part I; $66 \%$ in part II). These events are the goods that authors work with in constructing narratives. These particular local events, identified as salient enough to be included in a narrative, are selected from the immense universe of local incidents that all persons encounter. Like local events, cognitive events are evenly distributed between the becoming story and the being story, constituting about $25 \%$ of all elements. The composition of the becoming and being stories is similar. What differs is the structure built out of these raw materials. ${ }^{20}$

\section{Dyadic structure: Pattern across types of elements}

We begin by examining the dyadic structure of narrative links between types of elements. Table 2 reports the frequency of ties between elements of different types in each part of the narrative. Though the becoming story is twice as dense as the being story, the pattern of linkages between types of elements is in some respects similar in the two parts of the narrative.

While sharing some patterns, there are important differences between the two halves of the story. The most notable deviation is the role cognitions play in the two parts of the story. In the becoming story, cognitions are almost equally likely to send ties as to receive them (send-receive ratio $=0.86$ ), while in the being story, cognitions are almost always the consequence of a prior element (send-receive ratio = 0.16 ). Substantively, this reveals that cognitions play a crucial role in motivating the narrative of becoming. The cognitive labor of linking otherwise unrelated elements together is the hallmark of a narrative of identity formation. In the absence of cognitive glue, narrativity breaks down, as we observe in the narrative description of being a Nazi.

20 The goods that authors have to work with are roughly comparable. Meaning is derived from the way these goods are arrayed into a narrative and analyzed as a narrative network. 
Table 2

Network characteristics

\begin{tabular}{lrrrrrrr}
\hline & \multicolumn{2}{c}{ Becoming (Part I) } & \multicolumn{2}{c}{ Being (Part II) } & \multicolumn{2}{c}{ Entire Narrative } \\
\hline Types of ties & $\mathrm{n}$ & $\%$ & $\mathrm{n}$ & $\%$ & $\mathrm{n}$ & $\%$ \\
\hline M - L & 7 & 4 & 8 & 8 & 15 & 6 \\
M - C & 1 & 1 & 8 & 8 & 9 & 3 \\
L - L & 91 & 55 & 49 & 53 & 140 & 54 \\
L - C & 36 & 22 & 23 & 25 & 59 & 23 \\
C - L & 14 & 8 & 0 & 0 & 14 & 5 \\
C - C & 18 & 11 & 5 & 5 & 23 & 9 \\
\hline N of ties & 167 & & 93 & & 260 & \\
Overall density & 0.0174 & & 0.0093 & & 0.0066 & \\
\hline
\end{tabular}

Cognitions are densely interconnected with one another and with actual events. The production of cognitions appears to define sequences of actual events, and some cognitions reappear as the cause of subsequent action. This pattern is not replicated at all in the being narrative, where cognitions are relatively isolated from local events, and are never reflected back into the realm of action (i.e., into nodes coded as local event elements). Being a Nazi induces the absence of self-reflexivity.

Treating the narrative as a network reveals that though the same kinds of goods are used at the same frequency in each half of the story, how these goods get organized into narrative differs radically. The becoming narrative is a narrative because cognitions bridge event sub-sequences, driving the author to conceive of himself as a Nazi. In the being story, cognitions never bridge events or event sequences. This lack of organized connectivity yields a story that is marked by the absence of narrativity. The absence of narrativity results from the absence of a theory of the self.

\section{Element content in the becoming process}

As discussed earlier, standard life-stories produce their end (the life realized) by accretion of specific relational elements to the life-world of the narrator: roles, people, and places (Bruner, 1986). Our analysis of the structure of NSDAP narrative networks suggests that the new Nazi self emerges from the elision of social relations. The specific mechanism by which social relations are elided is physical mobility. The consequence of drifting in a world stripped of social relations is increasing commitment to simple cognitive abstractions that order experience into a set of binary oppositions and bridge between otherwise disjoint event sequences. The first two processes (breakdown and mobility) are characteristic processes associated with participation in high-risk and high-cost social movements (cf. biographical availability in McAdam, 1988). The latter process (simplification) is characteristic of radical conversion movements, typically those associated with a withdrawal from everyday life (Snow, 1986; Barker, 1984; Lofland and Stark, 1965). The coupling of 
breakdown and radical abstraction appears to yield the distinctive character of early Nazis.

The best way to measure the importance of particular kinds of events in narrative networks is to assess the centrality of nodes associated with them. Central nodes play a crucial role in advancing the narrative, because they weave together otherwise unconnected components of the story. We use a specific measure of centrality, 'power centrality', derived by Bonacich (1987), in which the centrality of each element is conditioned by the centrality of the elements it is tied to. In this formulation, an element with many ties to peripheral elements is not as central as an element with fewer ties to highly central elements. In narrative networks, power centrality captures the importance of each element in the plot that is unfolding.

The characteristic feature of the NSDAP becoming story is decreasing centrality of relational elements and traditional bases of identity (e.g., kin, church, school, and work) in the narrative of becoming. Ordinary social institutions, and the relations that they entail, become less and less central as the narrative progresses. At the start of our illustrative narrative, the author still acts in some of these settings he continues to see his family, he goes to school but his action becomes oriented elsewhere. The narrative sub-sequences associated with social roles are stories of rejection. A subtext of this narrative is shearing away from the dependencies of childhood and adolescence. ${ }^{21}$ Elision and breakdown is the first major theme of becoming.

The second major theme of the narrative of becoming is mobility. If breakdown creates a supply of potential Nazis, mobility operates as a matching mechanism, introducing persons to the movement. In the representative story, the nodes and sequences concerned with mobility in this narrative are the nodes that contain Nazis. This author experiences a great deal of mobility: he travels extensively, and changes residences often (nine times in three years). The consequences of his mobility are quite evident, since each time he travels, he encounters other Nazis. In short, his mobility experiences make possible encounters with NSDAP supporters, all of which draw him closer to the movement. Motion facilitates and sustains breakdown. The role played by travel and random contact gives the becoming story a flavor of chance or fate rather than agency.

Meaning is attached to the Nazi movement by organizing and resolving reality in terms of a series of simplified binary oppositions. In this case, the opposition of chaos and order organizes the narrative. By recounting the past in this way, the author exposes his own theory of becoming a Nazi, that the Hitler movement offered the solution to the chaos he saw everywhere around him. For example, in our illustrative story, one of the author's first thoughts is that nature is beautiful. This is rep-

21 The same pattern is present in almost all other becoming stories. One woman feels more and more like a Nazi as she progressively loses her eldest son, husband, and youngest son. With each loss she is drawn closer to the movement. The stories of older adherent's play on the losses experienced after the collapse of the war effort, the estrangement from place after the solidarity of the trenches. The story told by the author of our illustrative story is not out of the ordinary for a twentieth century youth. Individuals not firmly rooted in family, church, work, school, or other elements of civil society are biographically available to totalizing identities (Lofland and Stark, 1965; Stark and Bainbridge, 1979). It is not accidental that the Nazis attracted the youth of Germany. 
resented in Fig. 2 as the sequence of nodes 316, which culminates in node 23, the recognition that nature is beautiful. ${ }^{22}$ This love of nature becomes associated in his narrative with order- with straight rows of graves in cemeteries - order that is distinguished from the chaos of the republican period. ${ }^{23}$

The simplification of the world in terms of basic oppositions to which any content can be ascribed is the process that unites biographical availability with the contact afforded by mobility. This unification depends on the negation of particular social relations (for simplification rests on denial of difference), and allows the author to attach meaning to the movement he bumps into. The discovery of clarity (for this author the marker of being a Nazi) is hence revealed as more than a passive process: it rests on three 'microprocesses': breakdown, simplification, and motion.

Table 3 reports the relative centrality of substantively derived classes of elements in the becoming narrative associated with Fig. 2. We consider those elements associated with the micro-processes we have described, and compare their centrality to the narrative as a whole and to anti-Semitic components.

Table 3

Mean centrality and relative centrality of groups of elements

\begin{tabular}{llllllll}
\hline & N of Nodes & Chaos & $\begin{array}{l}\text { Exposure } \\
\text { to Nazis }\end{array}$ & $\begin{array}{l}\text { Anti- } \\
\text { semitism }\end{array}$ & Order & Elision & $\begin{array}{l}\text { Complete } \\
\text { narrative }\end{array}$ \\
\hline Chaos & 17 & $6.35^{\mathrm{a}}$ & $0.96^{\mathrm{b}}$ & 2.19 & 0.99 & 0.98 & 1.21 \\
Exposure to Nazis & 13 & & 6.60 & 2.28 & 1.02 & 1.02 & 1.26 \\
Anti-Semitism & 7 & & & 2.90 & 0.45 & 0.45 & 0.55 \\
Order & 9 & & & & 6.44 & 0.99 & 1.23 \\
Elision & 12 & & & & & 6.50 & 1.24 \\
\hline
\end{tabular}

Complete narrative $\quad 139$

5.24

“ Main diagonal cells report mean Bonacich centrality $($ beta $=0.2)$ for elements in group (Bonacich, 1987).

b Off-diagonal cells report the ratio of row to column group centrality (e.g., 6.35/6.60)

The centrality of exposure to Nazis (the consequence of mobility) deviates most markedly from the mean centrality of the first half of the narrative as a whole (ratio $=1.26$ ). The ideas of chaos and order are also significantly more central than other nodes. Elision of social relationships is also significantly more central than expected

\footnotetext{
22 This recognition happens when the author recovers from a childhood illness that has left him temporarily blinded.

23 Other elements in this process, by way of illustration are described immediately below. For example, when he first sees a parade of 'Hitler men"', (node 59), he compares them to the communists, who he has also seen in parades (node 26), and who have plundered his uncle's shop (nodes 30-33). At the age of 12 , he concludes that while both the communists and Nazis want power, the Hitler men sing beautifully and march well, and thus wouldn't harm anyone (nodes 71-73). At age 18 he reports that the Party fulfilled his 'inner longing for clarity', and that it was 'easy to act according to National Socialist ideas' (nodes 134-136).
} 
by chance. In this narrative, as in most others, anti-Semitism, while a common content, is characterized by low centrality. It is always in the background, but rarely drives the narrative. Centrality in a narrative network captures the dual characteristic of densely embedded nodes and reach. By focusing on centrality, narrative process at the level of element context is revealed. This process can, and does, differ from the explicit theory proposed by the author, for element centrality may be invisible in the unfolding narrative, as the most important nodes are those that bridge sub-sequences. While the life history is a theory of becoming, it reveals a process that is analytically distinct. The structure of a narrative network provides insight into motive, without exogenous imputation.

\section{Discussion}

The methodological goal of this article was to develop and illustrate a set of simple network based techniques for the analysis of complex narratives. The strategy we develop for working with narratives as networks rests on transforming the content elements of narrative (the goods that authors array into a sequence so as to construct a story) into nodes, connected by narrative clauses that can be seen as flows. This simple transformation allows for graphic representation of complex narratives. Because content elements (nodes) and the causal relations between elements (arcs) are abstracted from the raw narrative, the network graphs that result are isomorphic to the story from which they are drawn.

The key development is recognition that narratives and social structures have similar features, and that these features provide insight into the social meanings generated and reproduced within each. Both are often locally dense (and globally sparse), knotty, and redundant. These features of narratives, as with social structures, allow for measurement of their structural properties, thereby revealing their morphological foundation, and making possible meaningful comparisons, even across narrative contents (or structural contexts) that are vastly different in scope and significance. This article suggests that understanding this morphological foundation allows for new insight into the social meanings generated by narrative.

A byproduct of such understanding may be a third pathway for historical social science. More traditional interest and/or identity based models force analysts to impute motive to actors to bridge the gap between observed action and social context. Narrative network methods allow analysts to systematically utilize new data structures (life-stories, populations of interrelated event sequences) without having to wrest elements from their narrative context. This makes possible analysis of a new set of process-based questions, of which the becoming process discussed in this article is but one example of many.

In this case, measurement of the structural properties of narrative networks yields insight into the distinction between becoming and being. Focusing on the intercalation of element type and content with structural position reveals underlying narrative mechanisms; elision, mobility, and simplification. By reducing complex narratives to simpler images, we identify the specific nodes that are essential to the coherence 
of plot. The method we develop and illustrate in this article allows us to explore both structural features of narrative unfolding and the specific impact that cultural (content) elements play in becoming. In this instance, and in other NSDAP narratives, we observe the same general process: the Nazi self emerges from the elision of social relations through contact with other Nazis. The stories we consider are stories of the loss of relational identity. While the authors' theories directed the selection of elements to array into their life-stories, none of these authors set out to write stories of the loss of self. While narrative network graphs are isomorphic to the text, the meaning revealed from structural characteristics of the narrative as a whole, and the centrality and reach of specific elements, need not be the meaning 'intended' by the author. Structural similarity across heterogeneous narratives with respect to content suggests the presence of similar structural pathways for master-identity formation.

The structure of the narrative describing being a Nazi almost defies structural analysis. We cannot identify process in Fig. 2, for process requires connections, imputations, cognitive linking - in short, process requires narrative time, which is necessary for narrative clauses. When the process is completed when the author is a Nazi - the self disappears. Nothing is left to operate the story, except for a mechanical agency. This mechanical agency is the agency of a thermometer that in its very essence can only tell you the temperature; that is, an agency completely built into its being as a thermometer (Burke, 1945). The authors of the stories we consider can continue to report the facts, but nothing beyond the facts. This is not because there is not a story to tell: they explicitly select facts to tell a story, but it is a banal story of action without actors.

\section{References}

Abel, Theodor, 1938. Why Hitler came into power: An answer based on the original life stories of six hundred of his followers. New York: Prentice Hall.

Anderson, Benedict, 1991. Imagined communities. London: Verso.

Arendt, Hannah, 1973. The origins of totalitarianism. New York: Harvest/HJB.

Barker, Eileen, 1984. The making of a moonie; Brainwashing or choice. Oxford: Blackwell.

Bearman, Peter, 1993. Relations into rhetorics . New Brunswick, NJ: ASA Rose Monograph Series.

Bearman, Peter, 1999. Blocking the future. Ms., Columbia University.

Bonacich, Philip, 1987. Power and centrality: A family of measures. American Journal of Sociology 92 , 1170-1182.

Bourdieu, Pierre, 1990. The logic of practice. Stanford, CA: Stanford University Press.

Bruner, Jerome, 1986. Actual minds, possible worlds. Cambridge, MA: Harvard University Press.

Brustein, William, 1996. The logic of evil: The social origins of the nazi party, 1925-1933. New Haven, CT: Yale University Press.

Burke, Kenneth, 1945. A grammar of motives. New York: Prentice Hall.

Cain, Carole, 1987. Cultural models in language and thought. Edited by Dorothy Holland and Naomi Quinn. New York: Cambridge University Press.

Clausen, John A., 1993. American lives: Looking back at the children of the great depression. New York: Free Press.

Elder, Glen, 1974. Children of the great depression: Social change in life experience. Chicago, IL: University of Chicago Press.

Emirbyer, Mustafa and Jeff Goodwin, 1994. Network analysis, culture, and the problem of agency. American Journal of Sociology 99, 1411-1454. 
Gould, Roger V., 1995. Insurgent identities: Class, community, and protest in paris from 1848 to the commune. Chicago, IL: University of Chicago Press.

Kater, Michael H., 1983. The Nazi party: A social profile of members and leaders, 1919-1945. Cambridge, MA: Harvard University Press.

Kim, Hyjoung and Peter Bearman, 1997. The structure and dynamics of movement participation. American Sociological Review 62, 70-93.

Labov, William, 1972. Language in the inner city. Philadelphia, PA: University of Pennsylvania Press.

Labov, William and David Fanshel, 1977. Therapeutic discourse: Psychotherapy as conversation. New York: Academic Press.

Lofland, John and Rodney Stark, 1965. Becoming a world-saver: A theory of conversion to a deviant perspective. American Sociological Review 30, 862-818.

Marx, Karl, 1963. The eighteenth brumaire of Louis Bonaparte. New York: International Publishers.

McAdam, Doug, 1988. Freedom summer. New York: Oxford University Press.

Merkl, Peter H., 1977. Political violence under the swastika: 581 early Nazis. Princeton, NJ: Princeton University Press.

Mische, Anne and Philippa Pattison, 2000. The plurality of civic relations: Publics, projects, and social settings. Poetics 27, 163-193.

Mohr, John and Vincent Duquenne, 1998. The duality of culture and practice: Poverty relief in New York City, 1888-1917. Theory and Society 26/2-3, 305-356.

Peacock, James, 1986. Pentecostal and primitive baptist: Comparative life histories. Social Science 71, 46-53.

Rhodes, James, 1980. The Hitler movement. Stanford, CA: Hoover Institution Press.

Snow, David A., 1986. Frame alignment processes, micro-processes, and movement participation. American Sociological Review 51, 464-481.

Stark, Rodney and William Sims Bainbridge, 1979. Of churches, sects, and cults: Preliminary concepts for a theory of religious movements. Journal for the Scientific Study of Religions 18, 117-131.

Traugott, Mark, 1985. Armies of the poor: Determinants of working-class participation in the Parisian insurrection of 1848. Princeton, NJ: Princeton University Press.

Willis, Paul, 1977. Learning to labour: How working class kids get working class jobs. New York: Columbia University Press. 